\title{
STUDIES ON HUMAN SERUM PARAOXONASE/ARYLESTERASE
}

\author{
BERT N. LA DU ${ }^{a}$, STEVE ADKINS ${ }^{b}$, CHUNG-LIANG KUO ${ }^{b}$ and DAVID LIPSIGa \\ ${ }^{a}$ Departments of Pharmacology and Anesthesiology, Medical School, University of Michigan, Ann \\ Arbor, MI 48109-0572 and 'Department of Environmental and Industrial Health, School of Public \\ Health, University of Michigan, Ann Arbor, MI 48109-2029 (USA)
}

\section{SUMMARY}

The complete amino acid sequence of human serum paraoxonase/arylesterase and the DNA sequence coding for that protein have recently been determined in two independent laboratories. There is now considerable evidence that the esterase exists in two genetically determined allozymic forms, and these A and B allozymes possess both paraoxonase and arylesterase activities. The B-type esterase has relatively higher paraoxonase activity and is stimulated to a greater degree by $1 \mathrm{M} \mathrm{NaCl}$ than the A allozyme. The structural basis for the distinctive isozymic properties is a single nucleotide base at position 572. Codon 191 is CAA (for glutamine) in the A-type esterase, and CGA (for arginine) in the B-type enzyme. There is a second polymorphic site which affects amino acid 54; this can be either methionine or leucine, but these alternatives have not been found to affect either the level or the quality of the allozymes. Purified A or B-type esterases are stimulated by the addition of phosphatidylcholine. The latter addition increases the maximum velocity rate, but does not alter the $K_{\mathrm{m}}$ of the reaction with either paraoxon or phenylacetate. In serum, the esterase is tightly bound to the high density lipoproteins, particularly apo A-1, but the importance of this association as far as the stability and catalytic properties of the esterase is not clear, and still under study. No physiological role of the esterase has been established, but its ability to hydrolyze several potent organophosphates may be of some significance in protecting against organophosphate toxicity.

Key words: Paraoxonase purification - Serum arylesterase characteristics Organophosphate hydrolysis - Polymorphic isozymes

Correspondence to: Bert N. La Du, Department of Anesthesiology, Research Laboratories, R4038 Kresge Medical Research II, University of Michigan Medical School, Ann Arbor, MI 48109-0572, USA. 
Molecular biology studies on paraoxonase/arylesterase over the last two years in our laboratory [1] and by Furlong's group [2] have supported the model we proposed in 1983 [3]: that the human serum esterase exists in two closely related isozymic forms ( $\mathrm{A}$ and $\mathrm{B}$ ); that the two allozymes can hydrolyze both organophosphates and aromatic esters such as phenylacetate; and that isozyme $B$ has a much higher turnover number for paraoxon than isozyme $A$. The affinity of the esterase in serum for binding tightly with other lipoproteins and to aggregate with such components may explain why another laboratory described several molecular forms of the esterase in serum, some of which appeared to have only paraoxonase or arylesterase activity [4]. However, the cloning and sequencing of the cDNA coding for the enzyme in the two laboratories leaves little doubt that two major isozymic forms ( $\mathrm{A}$ and $\mathrm{B}$ ) must be responsible in some way for what appear to be contrary observations from other laboratories (see La Du [5]).

The enzyme has been highly purified from human serum in our laboratory and has a molecular weight of about $43.0 \mathrm{kDa}$ [6]. It requires calcium for stability as well as its catalytic activity with either phenylacetate or paraoxon. Our method of purification of the enzyme and the basic characteristics of the isozymes have recently been published $[6,7]$. Several laboratories have estimated the allelic frequencies of the paraoxonase polymorphism in ethnic groups in different parts of the world [8-11], but most of these estimates are based on measuring paraoxonase levels, alone, rather than by a method which distinguishes individual phenotypes (see La Du [5]). The recent progress in the molecular analyses of the polymorphism should make it simpler to relate phenotypes and genotypes, and estimate allelic frequencies more accurately. The molecular studies have not yet helped us to understand the possible physiological function of the esterase, its significance in endogenous metabolism, or its close association with the HDL complex.

This report will summarize some of the recent molecular and catalytic studies on human serum paraoxonase/arylesterase in our laboratory.

\section{MATERIALS AND METHODS}

Paraoxonase/arylesterase was purified from human serum previously phenotyped so that individual units of the same $A, A B$, or $B$ phenotype could be pooled. The purification method was developed in our laboratory [6], and we were able to obtain large quantities of enzyme of over $50 \%$ purity, with small amounts of albumin and apolipoprotein A-1 as impurities. Estimates of paraoxonase and arylesterase activities and the phenotyping of individual sera were carried out as described previously [3,12]. Ratios of paraoxonase activity in the presence of $1 \mathrm{M} \mathrm{NaCl}$ divided by the arylesterase activity were used to identify individual phenotypes, as follows: type $\mathrm{A}, 1.21 \pm 0.19$; type $\mathrm{AB}, 4.68 \pm 0.85$, and type B, $8.36 \pm 0.07$ (means \pm S.D.).

For sequencing of the DNA in the polymorphic regions, DNA was isolated 
from blood samples (buffy coat) by the salt-chloroform extraction method of Mullenbach [13]. Both polymorphic sites were near intron-exon junctions, so PCR primers were used which bridged the junctions to amplify the regions corresponding to amino acids 54 and 191. These gave products of about 180 and 230 base pairs (bp), respectively. Sequencing primers synthesized by the University of Michigan DNA Sequencing Facility and Oligos Etc. (Wilson, OR) were then used for direct sequencing of the polymorphic segments after PCR amplification to determine individual genotypes, as we recently reported [14].

Phospholipids tested for their effects on arylesterase and paraoxonase activities with purified serum esterase were obtained from Sigma Chemical Co., St. Louis, MO. These were mixed in a buffer and dispersed by sonication, then premixed with preparations of the esterase at $37{ }^{\circ} \mathrm{C}$ for about $30 \mathrm{~min}$ before the enzymatic assays.

\section{RESULTS AND DISCUSSION}

\section{Amino acid sequence of human serum paraoxonase/arylesterase}

The amino acid sequence of the mature protein and the location of the two polymorphic sites of human serum paraoxonase/arylesterase are shown in Fig. 1. Although the amino acid sequence shown has been deduced from our analyses of genomic DNA and liver cDNA nucleotide sequences, nearly $45 \%$ of the total amino acid sequence was confirmed in our laboratory by direct sequencing of tryptic and peptic digest peptides derived from the purified esterase [14]. Evidence for the polymorphism at position 191 was also obtained from high pressure liquid chromatography analysis of unique peptides identified in the tryptic digest profiles from purified A- and B-type esterases [14,15].

One interesting feature of the esterase structure, as first noted by Hassett et al. [2], is the unusual concentration of hydrophobic amino acid residues at the amino terminal end of the protein. It appears to represent the retention of a modified leader sequence. Presumably, a mutation altered the leader sequence and prevented removal of this hydrophobic region. No doubt, its presence helps account for the tendency of this protein to bind to other proteins, and aggregate by itself.

There are 354 amino acids in the mature protein with only 3 cysteine residues. Two of these are near the ends of the protein; the third is residue number 283. In our sequencing of tryptic digest peptides from purified esterase without reduction, a disulfide bridge linking two tryptic peptides was found. One of these was at the amino terminal end, and the other was near the carboxyl terminal position (Fig. 2). These were subsequently sequenced after reduction and separation to verify their locations. These results suggest that the ends of the native protein are linked by a disulfide bond, and this would leave only the cysteine at position 283 as the likely candidate for being a key component in the active center of this esterase.

\section{Analysis of the structural polymorphisms}

Variations in the amino acid residues at positions 54 and 191 were noticed by 
Ala Lys Leu Ihe Ala Leu Thr Leu Leu Gly Met Gly Leu Ala Leu Phe Arg Asn His Gln Ser Ser Tyr Gln Thr $\begin{array}{lllll}30 & 35 & 40 & 45 & \end{array}$

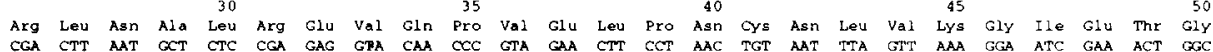

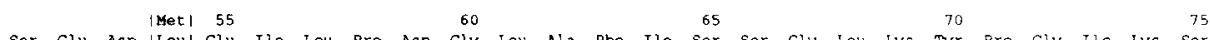

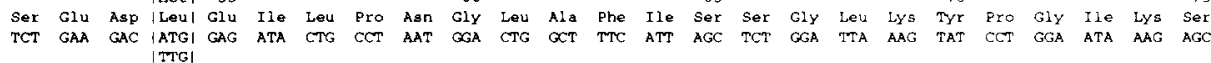
$\begin{array}{rrrrr}80 & 85 & 90 & 95 & 100\end{array}$

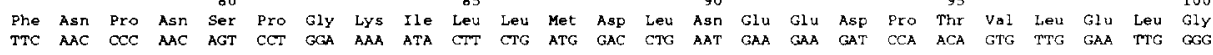
Ile thr Gly ser lys phe Asp Val ser Ser phe Asn pro His Gly Ile Ser thr phe thr Asp Glu Asp Asn Ala

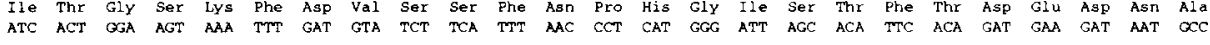
Met TYC LOU $13001350140 \quad 1450$

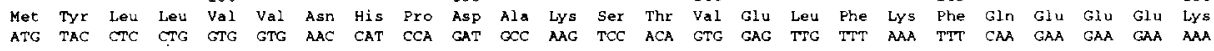
$1550160 \quad 1650170 \quad 175$

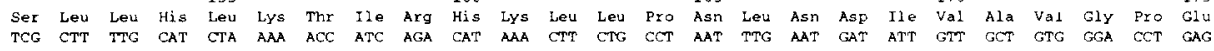

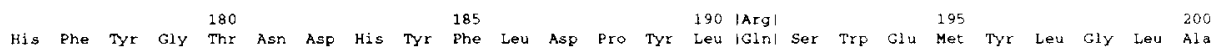

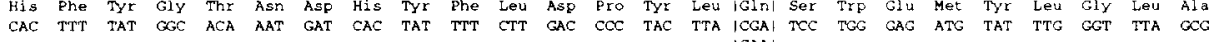

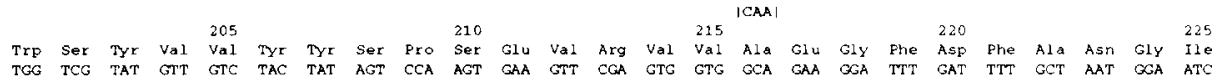
Asn tle ser pro Asp Gly LYs Tyr Val Tyr Ile Ala Glu Leu Leu Als his lys Ile His yal tyr Glu Lys His

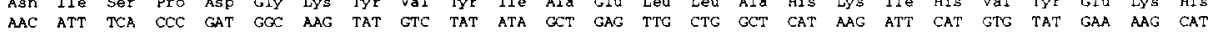

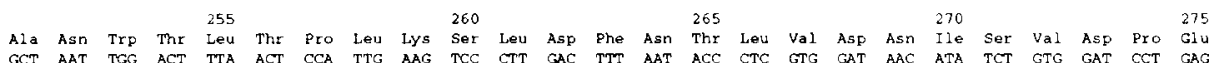

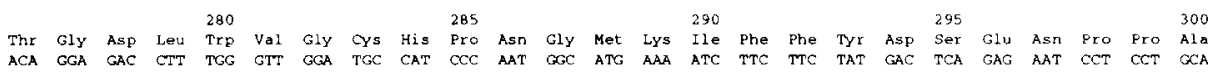
Ser Glu Val Leu Arg Ile Gln Asn Ile Leu Thr Glu Glu pro Lys Val Thr Gin Val tyr Ala Glu Asn Gly Thr

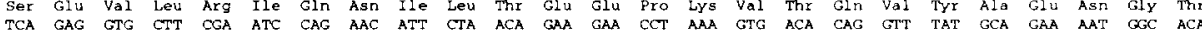
Val Le Gln Gly 330 Ther Val Ala Ser 335 Val $340 \quad 350$

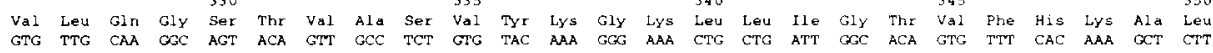
$\begin{array}{llll}\text { TYr } & \text { CYs } & \text { Glu Leu } \\ \text { TAC } & \text { TGT } & \text { GAG } & \text { CTC }\end{array}$

Fig. 1. Amino acid sequence and codons for human serum paraoxonase/arylesterase. The locations of the two polymorphic sites at residues 54 and 191 are indicated. (modified from Ref. 14).

\section{N-Terminal Peptide}

GLU VAL GLN PRO VAL GLU LEU PRO ASN CYS ASN LEU VAL LYS 45
1
$S$
1
$S$
1
ALA LEU TYR CYS GLU LEU 354

\section{C-Terminal Peptide}

Fig. 2. Amino acid sequences of disulfide-linked peptides obtained by tryptic digestion of purified human serum paraoxonase/arylesterase. 
Furlong's laboratory [2] and our laboratory [14,15]. At amino acid residue 54, it was methionine or leucine, and at position 191 it was glutamine or arginine. The two residues at one of these positions, alone, might explain the paraoxonase/arylesterase polymorphism, or certain combinations within the four isomers could be required. It was thus necessary to compare the genotypes obtained by direct sequencing of the PCR amplified genomic DNA at the two polymorphic sites with phenotyping results from serum of the same individuals.

Blood samples from twenty-seven unrelated volunteers were phenotyped by their ratios of paraoxonase activity in the presence of $1 \mathrm{M} \mathrm{NaCl}$ divided by their arylesterase activity (Fig. 3), and their DNA samples were used to sequence the two polymorphic regions after PCR amplification. The results of these analyses

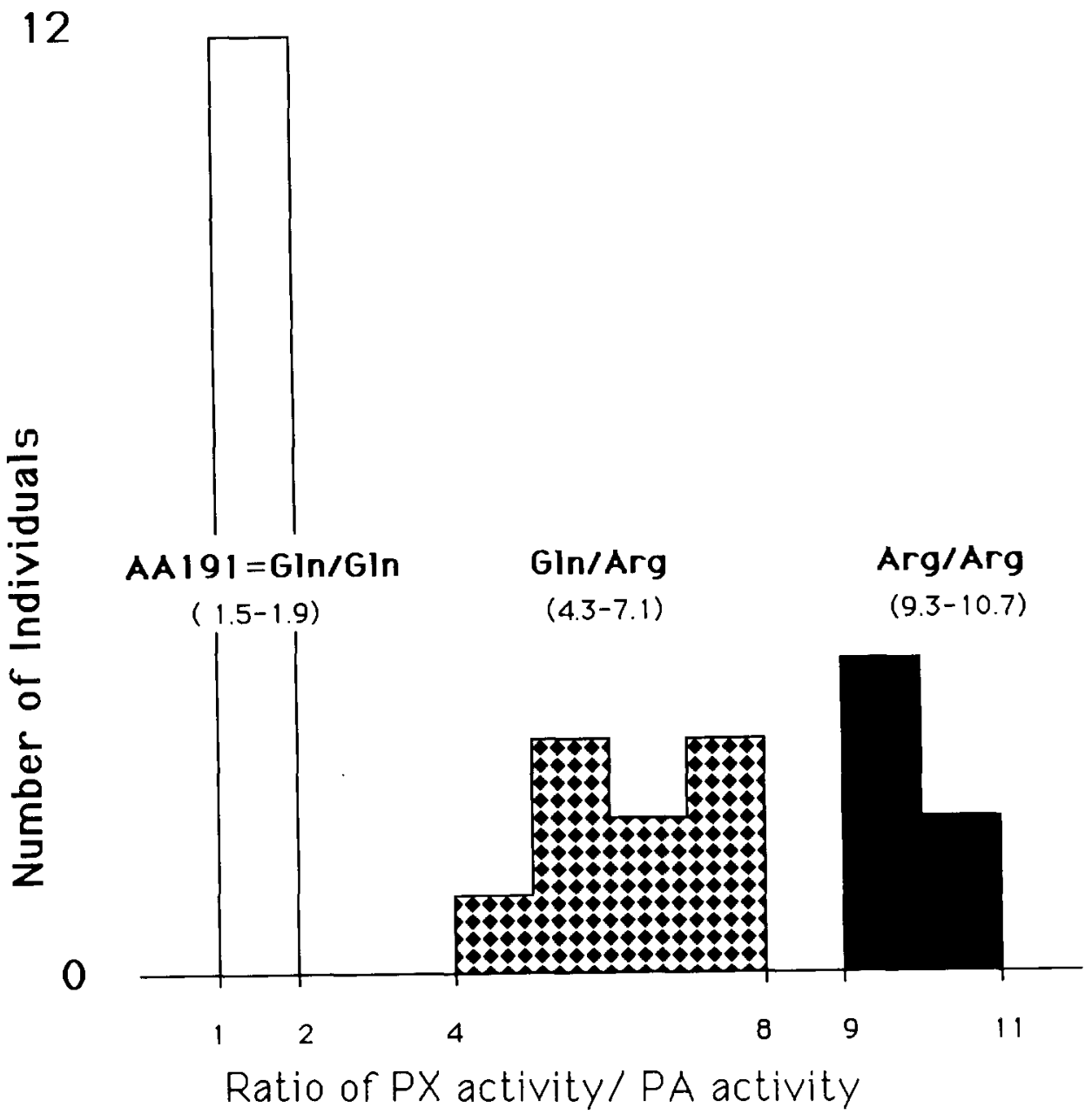

Fig. 3. Distribution of ratios of paraoxonase activity in the presence of $1 \mathrm{M} \mathrm{NaCl}$ divided by the arylesterase activity of 27 unrelated individuals. The three modes correspond to the A, AB and B phenotypes. 
are shown in Table I. Comparison of the serum esterase phenotypes and the DNA analyses showed that the amino acid at position 191 coincided exactly with the serum enzyme phenotype in every individual. All those of phenotype A had glutamine, and those of phenotype $B$ all had arginine at position 191; heterozygous individuals $(\mathrm{AB})$ had both of these amino acids represented. On the other hand, the methionine/leucine polymorphism determined by the codon for position 54 did not affect the serum phenotype in any obvious way. It is of interest that all B-type individuals were homozygous for leucine at the latter site, but this may simply be the result of linkage disequilibrium since these genetic markers are very close. The perfect agreement between the amino acids at position 191 and the serum esterase phenotypes in the individuals indicates that gene frequencies estimated from either of these traits would be the same. In contrast,

TABLE I

CORRELATION OF SERUM PARAOXONASE PHENOTYPES AND DNA GENOTYPES IN 27 UNRELATED INDIVIDUALS

\begin{tabular}{|c|c|c|c|c|c|c|}
\hline \multirow{2}{*}{$\begin{array}{l}\text { Serum } \\
\text { phenotype }\end{array}$} & \multirow[t]{2}{*}{ Individual } & \multirow{2}{*}{$\frac{\mu \text { Moles } \mathrm{PA}^{\mathrm{a}}}{\operatorname{Min} \times \mathrm{ml}}$} & \multirow{2}{*}{$\frac{\mathrm{nMoles} \mathrm{PX}^{\mathrm{b}}}{\operatorname{Min} \times \mathrm{ml}}$} & \multirow{2}{*}{$\begin{array}{l}\mathrm{PX} / \mathrm{PA} \\
\text { ratio }\end{array}$} & \multirow{2}{*}{$\begin{array}{l}\text { Amino } \\
\text { acid } 191\end{array}$} & \multirow{2}{*}{$\begin{array}{l}\text { Amino } \\
\text { acid } 54\end{array}$} \\
\hline & & & & & & \\
\hline $\mathrm{A}$ & D.Li & 95 & 155 & 1.6 & GLN,GLN & MET,MET \\
\hline A & L.S. & 100 & 169 & 1.7 & GIN,GLN & MET,MET \\
\hline $\mathrm{A}$ & R.S. & 100 & 191 & 1.9 & GLN,GLN & MET,MET \\
\hline A & S.V. & 82 & 152 & 1.9 & GLN,GLN & MET,MET \\
\hline A & S.P. & 98 & 169 & 1.7 & GLN,GLN & MET,LEU \\
\hline A & J.K. & 62 & 105 & 1.7 & GLN,GLN & MET,LEU \\
\hline A & A.H & 122 & 212 & 1.7 & GLN,GLN & MET,LEU \\
\hline A & W.W. & 89 & 157 & 1.8 & GLN,GLN & MET,LEU \\
\hline A & S.L. & 134 & 223 & 1.7 & GLN,GLN & LEU,LEU \\
\hline A & D.La & 86 & 162 & 1.9 & GLN,GLN & LEU,LEU \\
\hline A & P.C. & 129 & 201 & 1.6 & GLN,GLN & LEU,LEU \\
\hline A & E.L. & 118 & 176 & 1.5 & GLN,GLN & LEU,LEU \\
\hline$A B$ & S.A. & 58 & 321 & 5.6 & GLN,ARG & MET,MET \\
\hline $\mathrm{AB}$ & K.D. & 100 & 627 & 6.3 & GLN,ARG & MET,MET \\
\hline$A B$ & B.D. & 81 & 496 & 6.1 & GLN,ARG & MET,LEU \\
\hline $\mathrm{AB}$ & J.De & 141 & 784 & 5.6 & GLN,ARG & MET,LEU \\
\hline $\mathrm{AB}$ & T.I. & 57 & 398 & 7.0 & GLN,ARG & MET,LEU \\
\hline $\mathrm{AB}$ & H.C. & 51 & 355 & 7.0 & GLN,ARG & MET,LEU \\
\hline $\mathrm{AB}$ & K.C. & 114 & 496 & 4.3 & GLN,ARG & LEU,LEU \\
\hline $\mathrm{AB}$ & L.Z. & 129 & 758 & 5.9 & GLN,ARG & LEU,LEU \\
\hline $\mathrm{AB}$ & M.G. & 110 & 780 & 7.1 & GLN,ARG & LEU,LEU \\
\hline B & M.S. & 91 & 846 & 9.3 & $\mathrm{ARG}, \mathrm{ARG}$ & LEU,LEU \\
\hline B & B.L. & 86 & 890 & 10.3 & ARG,ARG & LEU,LEU \\
\hline $\mathrm{B}$ & A.T. & 106 & 1006 & 9.5 & $\mathrm{ARG}, \mathrm{ARG}$ & LEU,LEU \\
\hline B & $\mathrm{J} . \mathrm{Da}$ & 76 & 737 & 9.7 & ARG,ARG & LEU,LEU \\
\hline B & A.C. & 100 & 1063 & 10.7 & $\mathrm{ARG}, \mathrm{ARG}$ & LEU,LEU \\
\hline B & J.V. & 106 & 1020 & 9.7 & ARG,ARG & LEU,LEU \\
\hline
\end{tabular}

\footnotetext{
a Phenylacetate.

b Paraoxon in the presence of $1 \mathrm{M} \mathrm{NaCl}$.
} 
the frequencies of the methionine/leucine polymorphic choices at residue $54 \mathrm{did}$ not show a similar agreement. It is, none the less, a very common polymorphism, and its importance must still be determined.

A schematic representation of the enzyme structure showing the free sulfhydryl group (cysteine), the single internal disulfide bridge, the two polymorphic sites, and the location of four possible carbohydrate chains based on the requisite amino acid sequence is shown in Fig. 4.

Stimulation of esterase activity by phospholipids

It has been observed that with higher purification of the serum paraox-

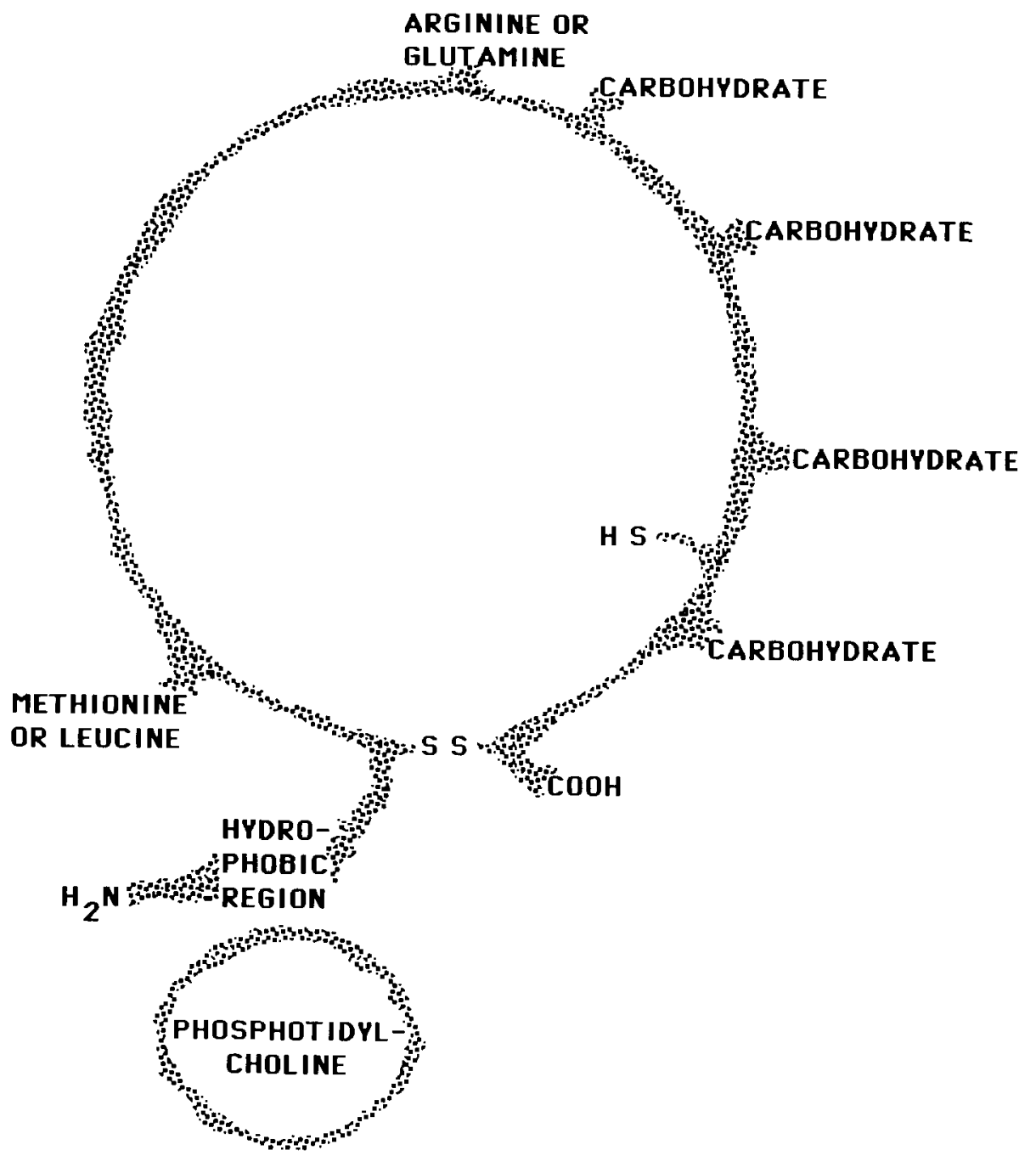

Fig. 4. Schematic representation of the paraoxonase/arylesterase enzyme showing the polymorphic sites, hydrophobic $\mathrm{N}$-terminal segment, the disulfide bridge and single free sulfhydryl residue. 
onase/arylesterase some loss of activity regularly takes place, but this loss can be largely regained by adding back certain fractions obtained during the DEAE column chromatography step. We analyzed these fractions and found that they were enriched in phospholipids. When we substituted purified dilauroyl phosphatidylcholine, a maximal degree of stimulation was obtained (Table II). Commercial lecithin preparations and most other phospholipids were somewhat less effective; phosphatidyl-serine was inhibitory. A comparison of the effectiveness of the compounds shows that there is some degree of specificity for this effect, and saturated medium length fatty acids were more effective than the other analogs. We now suspect that some of our earlier observations on protective or stimulatory effects obtained by combining apolipoprotein A-1 with the purified esterase were probably due to the phospholipid content of the mixture. We have yet to see a clear beneficial effect of apolipoprotein A-1 with the purified esterase when there is also an optimal concentration of choline-containing phospholipids. Among the compounds not effective in place of the phosphatidylcholine were tripalmitin, sphingomyelin, and phosphatidylinositol. Simple lipids, then, are not all stimulatory like selective phospholipids. Dilauroyl phosphatidylcholine does not change the $K_{\mathrm{m}}$ appreciably, but it increases the $V_{\max }$ of the reaction. Thus, the phosphatidylcholine is not simply facilitating the interaction of substrate with the enzyme, but is making the enzyme a more efficient catalyst, and presumably is increasing the turnover number of the esterase with either paraoxon or phenylacetate (Fig. 5).

The very close association of serum paraoxonase/arylesterase with apolipoprotein A-1 and with phosphatidylcholine may take place through the hydrophobic region at the amino terminus of the enzyme. However, a more exact understanding of the interactions of the esterase with these components will be possible after we obtain the three-dimensional characteristics of the molecule by crystallographic analysis.

TABLE II

STIMULATION OF PHENYLACETATE HYDROLYSIS BY PHOSPHATIDYLCHOLINE AND ANALOGUES

\begin{tabular}{lcc}
\hline Compound & \% Inhibition & \% Stimulation \\
\hline Dilauroyl-PC & & 65.0 \\
Dioleoyl-PC & & 56.3 \\
Lecithin & & 41.1 \\
Lysolecithin & & 31.6 \\
Phosphatidylethanolamine & 18.6 \\
Phosphatidylglycerol & 33.3 & 9.6 \\
Phosphatidylserine & 37.4 & \\
6-palmityl-ascorbic acid & \\
\hline
\end{tabular}

No effect: Tripalmitin, cholesterylacetate, sphingomyelin, cardiolipid, phosphatidylinositol, vitamin $\mathrm{K} 3$, glycerophosphorylcholine. (Control activity: $64.4 \mathrm{U} / \mathrm{ml}$.) 


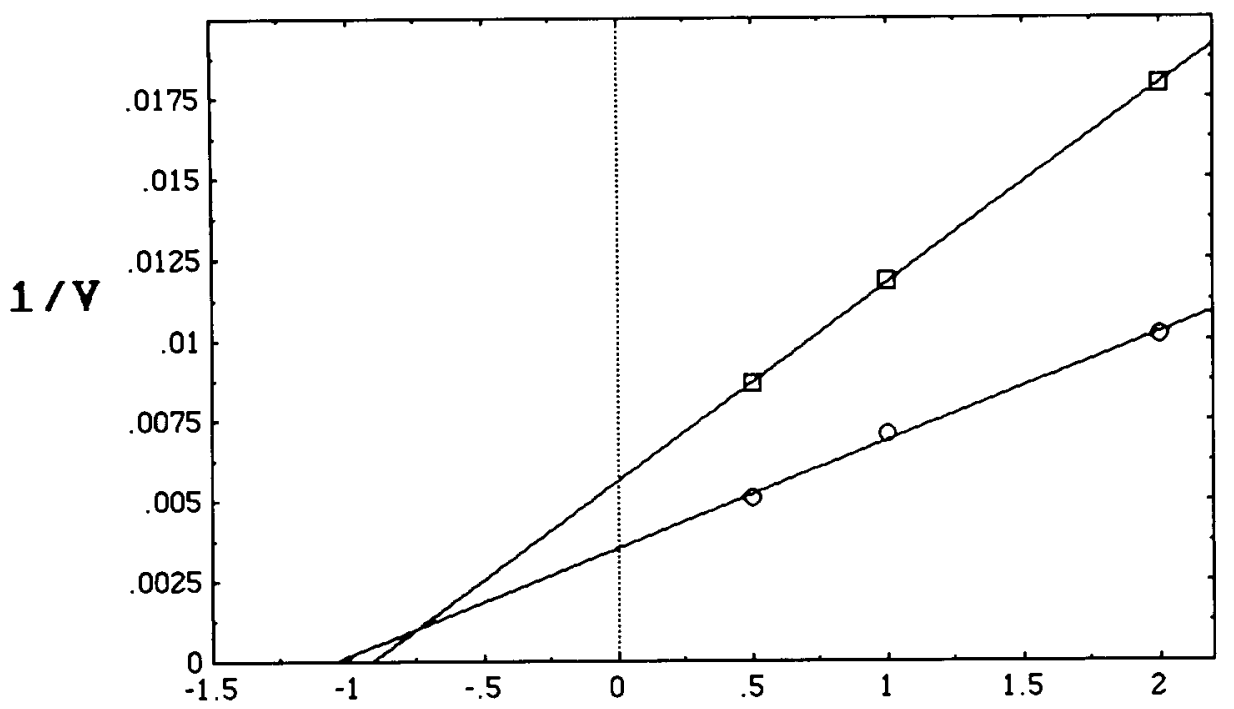

\section{$1 / S$}

Fig. 5. Effect of dilauroyl phosphatidylcholine on arylesterase activity of purified human serum paraoxonase/arylesterase. Squares indicate enzyme alone and circles indicate enzyme with dilauroyl phosphatidylcholine.

\section{ACKNOWLEDGEMENTS}

The support of Grant GM 46979 from the National Institute of General Medical Sciences is gratefully acknowledged.

\section{REFERENCES}

1 S. Adkins, K.N. Gan, M. Mody and B.N. La Du, Purification and cloning of human serum paraoxonase/arylesterase, FASEB J., 5 (1991) A648.

2 C.Hassett, R.J. Richter, R. Humbert, C. Chapline, J.W. Crabb, C.J. Omiecinski and C.E. Furlong, Characterization of cDNA clones encoding rabbit and human serum paraoxonase: the mature protein retains its signal sequence, Biochemistry, 30 (1991) 10141-10149.

3 H. W. Eckerson, C.M. Wyte and B.N. La Du, The human serum paraoxonase/arylesterase polymorphism, Am. J. Hum. Genet., 35 (1983) 1126-1138.

4 M.I. Mackness, H.M. Thompson, A.R. Hardy and C.H. Walker, Distinction between 'A'esterases and arylesterases, Biochem. J., 245 (1987) $293-296$.

5 B.N. La Du, Human serum paraoxonase/arylesterase, in: W. Kalow (Ed.), Pharmacogenetics of Drug Metabolism, Pergamon Press, New York, 1992, pp. 51-91.

6 K.N. Gan, A. Smolen, H.W. Eckerson and B.N. La Du, Purification of human serum paraoxonase/arylesterase, evidence for one esterase catalyzing both activities, Drug Metab. Dispos., 19 (1991) 100- 106.

7 A. Smolen, H.W. Eckerson, K.N. Gan and B.N. La Du, Characteristics of the genetically determined allozymic forms of human serum paraoxonase/arylesterase, Drug Metab. Dispos., 19 (1991) 107-112. 
8 J.R. Playfer, L.C. Eze, M.F. Bullen and D.A.P. Evans, Genetic polymorphism and interethnic variability of plasma paraoxonase activity, J. Med. Genet., 13 (1976) 337-342.

9 H.W. Goedde, H.G. Rothhammer and P. Bogdanski, Ecogenetic studies in Atacameno Indians, Hum. Genet., 67 (1984) 343-346.

10 B.N. La Du, S. Adkins and R.A.-L. Bayoumi, Analysis of the serum paraoxonase/arylesterase polymorphism in some Sudanese families, in: W. Kalow, H.W. Goedde and D.P. Agarwal (Eds.), Ethnic Differences in Reactions to Drugs and Xenobiotics, Alan R. Liss, New York, 1986, pp. $87-98$.

11 M. Geldmacher-v, Mallinckrodt and T.L. Deipgen, The human paraoxonase polymorphism and specificity, Toxicol. Environ. Chem., 18 (1988) 79-196.

12 H.W. Eckerson, J. Romson, C. Wyte and B.N. La Du, The human serum paraoxonase polymorphism: identification of phenotypes by their response to salts, Am. J. Hum. Genet., 35 (1983) $214-227$.

13 R. Mullenbach, P.J.L. Lagoda and C. Welter, An efficient salt-chloroform extraction of DNA from blood and tissues, Trends Genet., 5 (1989) 391.

14 S. Adkins, K.N. Gan, M. Mody and B.N. La Du, Molecular basis for the polymorphic forms of human serum paraoxonase/arylesterase: glutamine or arginine at position 191 for the respective A or B allozymes, Am. J. Hum. Genet., 52 (1993) 598-608.

15 M. Mody, S. Adkins, K. Gan and B. La Du, Direct evidence from peptide sequencing for one amino acid difference in human serum paraoxonase/ arylesterase A and B isozymes, FASEB J., 6 (1992) A3741. 